\title{
Circulating miR-31 as an effective biomarker for detection and prognosis of human cancer: a meta-analysis
}

\author{
Yingjun Ma ${ }^{1, *}$, Yunfang Chen ${ }^{2, *}$, Jinbo Lin ${ }^{3, *}$, Yi Liư ${ }^{4}$, Kai Luo ${ }^{5}$, Yong Cao ${ }^{4}$, Tieqiang \\ Wang ${ }^{4}$, Hongwei Jin ${ }^{4}$, Zhan Su${ }^{4}$, Haolin $\mathrm{Wu}^{4}$, Xiaoliang Chen ${ }^{4}$, Jinquan Cheng ${ }^{6}$ \\ ${ }^{1}$ Respiratory Medicine, Guangming District People's Hospital of Shenzhen, Shenzhen, P.R. China \\ ${ }^{2}$ Pain Department, The Eight Affiliated Hospital, Sun Yat-sen University, Shenzhen, P.R. China \\ ${ }^{3}$ Medical oncology, Longgang District Central Hospital of Shenzhen, Shenzhen, P.R. China \\ ${ }^{4}$ Center for Chronic Disease Control and Prevention, Shenzhen Guangming District Center for Disease Control and Prevention, \\ Shenzhen, P.R. China \\ ${ }^{5}$ Affiliated Cancer Hospital \& Institute of Guangzhou Medical University, Guangzhou, P.R. China \\ ${ }^{6}$ Molecular Biology Laboratory, Shenzhen Center for Disease Control and Prevention, Shenzhen, P.R. China \\ *These authors have contributed equally to this work \\ Correspondence to: Xiaoliang Chen, email: 120497143@qq.com \\ Jinquan Cheng, email: cjinquan@szcdc.net
}

Keywords: miR-31, carcinoma, detection, prognosis, meta-analysis

Received: December 07, $2016 \quad$ Accepted: January 29, $2017 \quad$ Published: February 23, 2017

Copyright: Ma et al. This is an open-access article distributed under the terms of the Creative Commons Attribution License (CC-BY), which permits unrestricted use, distribution, and reproduction in any medium, provided the original author and source are credited.

\section{ABSTRACT}

Purpose: Circulating miR-31 was found to be associated with cancers detection and prognosis. The present meta-analysis aimed to explore the effect of circulating miR-31 on cancer detection and prognosis.

Method: The studies were accessed using multiple databases. RevMan5.3, MetaDiSc 1.4, and STATA14.0 were used to estimate the pooled effects, heterogeneity among studies, and publication bias.

Results: A total of 14 studies with 1397 cancer patients and 1039 controls were included. For the 12 prognostic tests, the adjusted pooled-AUC was 0.79 (95\% CI: 0.73-0.86) as the pooled sensitivity, specificity, positive likelihood ratio (PLR), negative likelihood ratio (NLR), diagnostic odd ratio (DOR) from 10 tests was 0.79 (95\% CI: $0.76-0.82$ ), 0.79 (95\% CI: 0.76-0.82), 3.81 (95\% CI: 2.90-5.01), 0.26 (95\% CI: 0.20$0.35)$, and 16.81 (95\% CI: 9.67-29.25), respectively. For the 5 prognosis analyses, the pooled HR (hazard ratio) of overall survival (OS) was 1.55 (95\% CI 1.30-1.86) for high versus low circulating miR-31 expression. However, high expression of circulating miR-31 did not significantly increase the risk of poor differentiation (pooled $O R=1.39$, 95\% CI: 0.56-3.47) and LNM (pooled OR=3.46, 95\% CI: 0.96-12.42) in lung cancer.

Conclusion: Circulating miR-31 is an effective biomarker and could be used as a component of miRs signature for cancer detection and prognosis surveillance.

\section{BACKGROUND}

MicroRNAs (miRNAs, miRs) are short, single stranded RNA molecules, which primarily bind messenger RNAs (mRNAs) at 3'UTRs via partial complementarity with the "seed sequence"[1]. MiRNAs serve as negative regulators of gene expression at the post-transcriptional level and have been widely implicated in pathogenesis of human diseases, especially cancer [2, 3]. Genomewide profiling has identified that miRNAs are frequently aberrantly expressed in human cancers. Experiments showed that miRNAs involved in tumorigenesis, angiogenesis, metastasis, and chemo-resistance by directly targeting specific oncogenes or tumor suppressors. As participated in many cellular cancer pathways including development, cell proliferation, differentiation, and 
apoptosis [4-6], miRNAs were expected to be crucial factors for cancer diagnosis and therapy as well as prognosis surveillance.

MiR-31, a highly evolutionarily conserved miRNA, plays an important regulating role in embryonic implantation, development, bone and muscle homeostasis, and immune function [7]. Abundant studies have reported that miR-31 was dysregulated in various human cancers, such as lung cancer [8], colorectal cancer [9], oral squamous cell carcinoma [10], cervical cancer [11], ovarian cancer [12], and upper tract urothelial carcinoma [13]. Abnormal expression of miR-31 in tumorous tissue has confirmed it involved in tumorigenesis and progression of cancers [1416]. Similar to being tested in cancer tissues, miR-31 could be steadily detected in circulating blood. The miR-31 level of circulating blood was positively correlated with that in cancer tissues [17]. Consequently, circulating miR-31 was used as a noninvasive biomarker for cancer detection and diagnosis [17-22]. Furthermore, circulating miR-31 was found associated with prognosis such as metastasis and survival $[18,19,22]$. However, the effect of circulating miR31 on cancer diagnosis and prognosis is controversial, and no meta-analysis has investigated the association between circulating miR-31 expression and diagnosis as well as prognosis of cancer. The present meta-analysis aimed to explore the role of circulating miR-31 on cancer detection/ diagnosis and further on prognosis surveillance of patients.

\section{RESULTS}

\section{Characteristics of eligible studies}

Fourteen eligible studies included in the metaanalysis (Figure 1), 11 from China [17, 19, 20, 22-29] and 3 from United States [18], Denmark [30], and Spain [21]. The studies involved 1397 cancer patients and 1039 controls, with mean sample size of 99.8 patients (range 20 to 300$)$. Seven types of cancer were evaluated: lung cancer $(n=4)$, colorectal cancer $(n=4)$, esophageal squamous cell carcinoma $(n=2)$, breast cancer, renal tumors, Pancreatic Cancer, Oral squamous cell carcinoma ( $\mathrm{n}=$ 1, each). The level of miR-31 was detected in circulating blood by RT-PCR. In the prognosis analysis, the group cutoff value determined by the original research depended on the median/mean value of miR-31 level or ROC (receiver operating characteristic curve) analysis. The main characteristics of each study are summarized in Table 1.

\section{Meta-analysis of circulating miR-31 for human cancer detecting}

\section{Assessment of quality}

In the 14 eligible studies, 10 studies presented the AUC (area under receiver operating characteristic curve) of circulating miR-31 on cancers detection/diagnosis with 1122 cases and 1039 controls, although only 8 studies had the values of sensitivity and specificity for the diagnosis tests. In addition, the participants in 2 studies were divided into two groups for testing and validation. Consequently, we assessed the overview quality of 12 diagnosis tests and reported them in Supplementary Figure 1. The risk of bias in patient selection was considered high in 11 (92\%) tests, mainly due to the 2-gate (case-control) design in the majority of tests. Because the diagnosis of all patients was known before the index test performed, the risk of bias of index test performance was considered high in 11 (92\%) studies. However, the risk of bias for reference standard definition was low in the majority of studies $(n=10 ; 83 \%)$; and the risk of bias arising from patient flow and timing of procedures was also low in the majority of studies $(n=8,67 \%)$. For the regarding applicability, there was low risk identified for patient selection $(\mathrm{n}=8,67 \%)$, reference standard $(\mathrm{n}=10$, $83 \%)$, and reference standard $(n=10,83 \%)$.

\section{Pooled diagnostic values}

Because of severe heterogeneity among 12 diagnosis tests $\left(I^{2}=99 \%, P_{Q}<0.0001\right)$, the random-effects model was used to calculate the pooled effect. As shown in Figure 2, the pooled AUC was 0.80 (95\% CI: 0.72-0.87). Because the value of sensitivity and specificity could not be obtained from 3 of the diagnosis tests, we further calculated the pooled effects derived from sensitivity and specificity in the 9 tests. When the threshold effect was not found among them (spearman coefficient $=-0.082$, $\left.P_{Q}=0.770\right)$, the pooled sensitivity, specificity, positive likelihood ratio (PLR), negative likelihood ratio (NLR), diagnostic odd ratio (DOR) was conducted with the value being 0.79 (95\% CI: 0.76-0.82), 0.79 (95\% CI: 0.76-0.82), 3.81 (95\% CI: 2.90-5.01), 0.26 (95\% CI: $0.20-0.35)$, and 16.81 (95\% CI: 9.67-29.25), respectively (Supplementary Figure 2). In addition, the summary operating characteristic curve (sROC) and the Fagan plot were shown in Figure 3 and Figure 4; and the area under sROC was 0.88 (95\% CI: 0.82-0.93). The diagnostic accuracy of miR-31 for cancers was relatively high.

Basing on the types of cancers included in the meta-analysis, we also pooled the effects for the cancer with more than 1 diagnosis tests. The pooled AUC was 0.78 (95\%CI: 0.76-0.81), 0.71 (95\%CI: 0.57-0.86), 0.88 (95\%CI: 0.82-0.93) for lung cancer, colorectal cancer, and esophageal cancer, respectively. The pooled sensitivity, specificity, PLR, NLR, and DOR of subgroup were presented in Table 2. There were no obvious differences among cancer types.

\section{Meta-analysis of circulating miR-31 for prognosis of human cancer}

\section{Association between circulating miR-31 and differentiation, LNM}

There were 3 and 4 studies reported the cases of poor differentiation and the cases of lymph node metastasis (LNM) by circulating miR-31 level, and 
all of them were the lung cancer patients. Because of significant heterogeneity among the studies (for differentiation: $\mathrm{I}^{2}=65 \%, P_{Q}=0.06$; for LNM: $\mathrm{I}^{2}=$ $\left.87 \%, P_{Q}<0.0001\right)$, the random-effects model was used. High expression of circulating miR-31 did not significantly increase the risk of poor differentiation (pooled $\mathrm{OR}=1.39,95 \% \mathrm{CI}: 0.56-3.47$ ) and $\mathrm{LNM}$ (pooled $\mathrm{OR}=3.46,95 \% \mathrm{CI}: 0.96-12.42$ ) in lung cancer (Supplementary Figure 3).

\section{Association between circulating miR-31 and OS}

Five studies showed data for OS (overall survival) by circulating miR-31 level for 612 cancer patients. Because of no heterogeneity $\left(I^{2}=25 \%, P_{Q}=0.25\right)$, the fixedeffects model was used. The pooled HR (hazard ratio) of OS was 1.55 (95\% CI 1.30-1.86) for high versus low circulating miR-31 expression (Figure 5), so high miR-223 expression significantly decreased the OS time.

\section{Sensitivity analysis}

Sensitivity analysis was conducted for the association between circulating miR-31 and cancer detection as well as cancer prognosis. For the cancer detection, each diagnosis test was deleted in turn to examine the influence of the removed data on the overall AUC. The value of pooled AUC remained above 0.50 throughout (data not shown). In addition, each of the 9 tests was also excluded sequentially; the summary sensitivity and specificity, PLR, NLR, and area under sROC were altered (data not shown). For the cancer

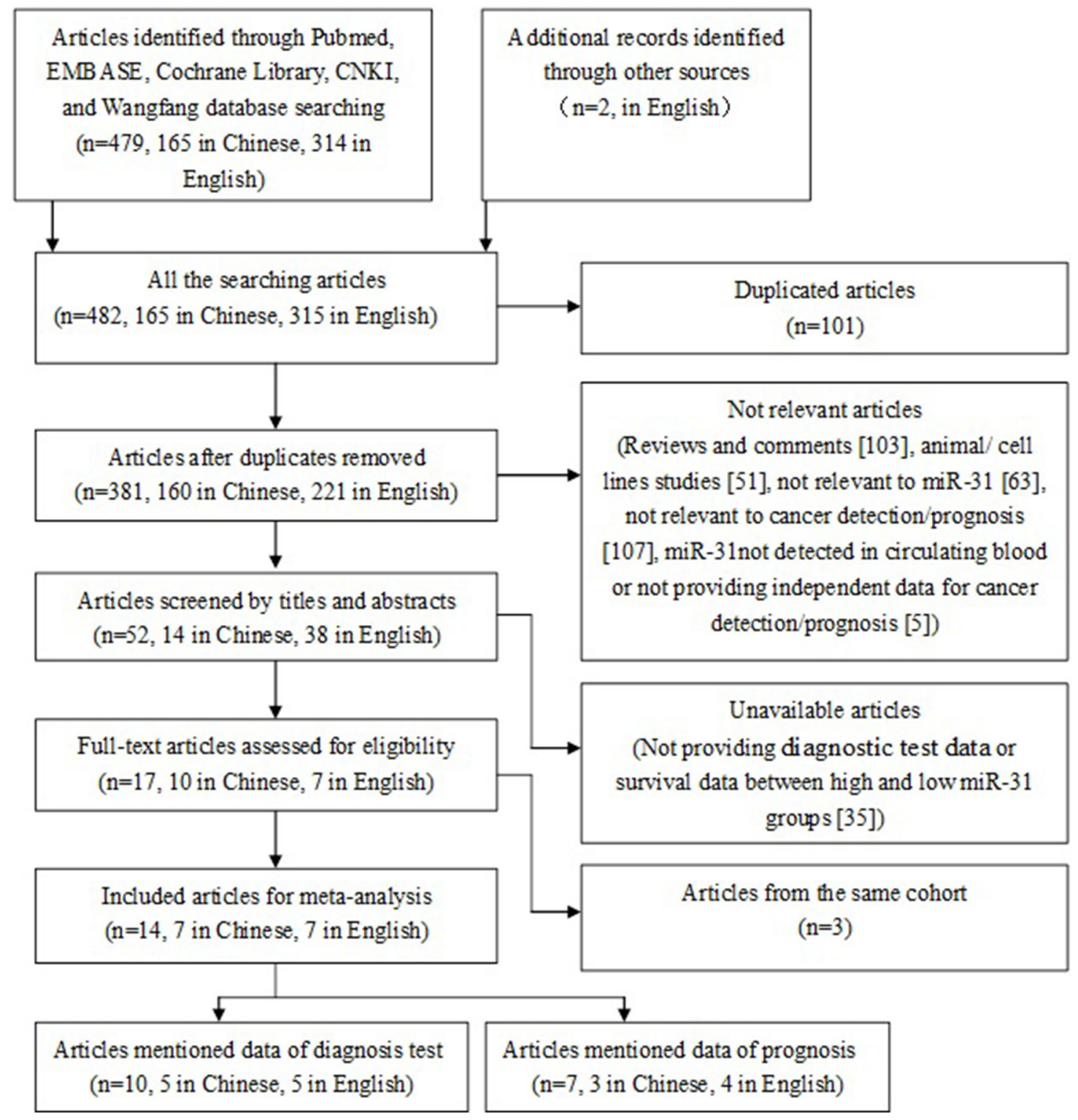

Figure 1: The flow chart of meta-analysis. 
Table 1: Basic data for all included studies in the meta-analysis

\begin{tabular}{|c|c|c|c|c|c|c|c|c|c|c|c|c|c|}
\hline \multirow[b]{2}{*}{ Author } & \multirow[b]{2}{*}{ Year } & \multirow[b]{2}{*}{ Derived } & \multirow{2}{*}{$\begin{array}{c}\text { Cancer } \\
\text { type }\end{array}$} & \multirow[b]{2}{*}{ Method } & \multicolumn{4}{|c|}{ Detection } & \multicolumn{5}{|c|}{ Prognosis } \\
\hline & & & & & $\begin{array}{c}\text { Case/ } \\
\text { control }\end{array}$ & $\begin{array}{c}\text { AUC } \\
\& 95 \% \text { CI }\end{array}$ & Sensitivity & Specificity & $\begin{array}{c}\text { Cases } \\
\text { (high/low) }\end{array}$ & $\begin{array}{c}\text { LNM } \\
\text { (high/low) }\end{array}$ & $\begin{array}{l}\text { Differentiation } \\
\text { (high/low) }\end{array}$ & Outcomes & NOS \\
\hline $\begin{array}{l}\text { Ali S. } \\
\text { et al. }\end{array}$ & 2015 & American & $\begin{array}{l}\text { Pancreatic } \\
\text { cancer }\end{array}$ & qt-PCR & NR & NR & NR & NR & $10 / 10$ & NR & NR & OS & 7 \\
\hline $\begin{array}{l}\text { Yan H. } \\
\text { et al. }\end{array}$ & 2015 & Chinese & Lung cancer & qt-PCR & $300 / 300$ & $\begin{array}{c}0.785 \\
(0.76-0.81)^{*}\end{array}$ & 0.769 & 0.745 & $168 / 132$ & $\begin{array}{l}\mathrm{Y}:(96 / 30), \\
\mathrm{N}:(72 / 102)\end{array}$ & $\begin{array}{l}\text { W:(45/27), } \\
\text { M:(60/51), } \\
\text { P:(63/54) }\end{array}$ & OS & 7 \\
\hline $\begin{array}{l}\text { Liu C. } \\
\text { et al. }\end{array}$ & 2010 & Chinese & $\begin{array}{c}\text { Oral } \\
\text { squamous cell } \\
\text { carcinoma }\end{array}$ & qt-PCR & $43 / 21$ & $\begin{array}{c}0.82 \\
(0.763-0.877)\end{array}$ & 0.627 & 0.994 & NR & NR & NR & NR & \\
\hline \multirow[t]{2}{*}{$\begin{array}{l}\text { Chang P. } \\
\text { et al. }\end{array}$} & 2015 & Chinese & $\begin{array}{l}\text { Colorectal } \\
\text { cancer }\end{array}$ & qt-PCR & $\begin{array}{l}\text { Test: } \\
(60 / 60)\end{array}$ & $\begin{array}{c}0.710 \\
(0.617-0.802)\end{array}$ & NR & NR & NR & NR & NR & NR & \\
\hline & & & & & $\begin{array}{l}\text { Validation: } \\
(121 / 153)\end{array}$ & $\begin{array}{c}0.559 \\
(0.491-0.627)\end{array}$ & NR & NR & & & & & \\
\hline $\begin{array}{l}\text { Schou J. } \\
\text { et al. }\end{array}$ & 2011 & Danish & $\begin{array}{l}\text { Colorectal } \\
\text { cancer }\end{array}$ & qt-PCR & NR & NR & NR & NR & $72 / 72$ & NR & NR & OS & 5 \\
\hline \multirow[t]{2}{*}{$\begin{array}{l}\text { Zhang T. } \\
\text { et al. }\end{array}$} & 2011 & Chinese & $\begin{array}{l}\text { Oesophageal } \\
\text { squamous cell } \\
\text { carcinoma }\end{array}$ & qt-PCR & $\begin{array}{c}\text { Test: } \\
(120 / 121)\end{array}$ & $\begin{array}{c}0.902 \\
(0.857- \\
0.936)\end{array}$ & 0.867 & 0.843 & $22 / 22$ & NR & NR & $\begin{array}{l}\text { RFS } \\
\text { TSS }\end{array}$ & 7 \\
\hline & & & & & $\begin{array}{c}\text { Validation: } \\
(81 / 81)\end{array}$ & $\begin{array}{c}0.888 \\
(0.819-0.939)\end{array}$ & 0.861 & 0.791 & & & & & \\
\hline $\begin{array}{l}\text { Ren X. } \\
\text { et al. }\end{array}$ & 2014 & Chinese & $\begin{array}{l}\text { Non-small } \\
\text { cell lung } \\
\text { cancer }\end{array}$ & qt-PCR & NR & NR & NR & NR & $34 / 29$ & $\begin{array}{l}Y:(31 / 10), \\
N:(3 / 19)\end{array}$ & $\begin{array}{c}\text { H+M: } \\
(15 / 24), \\
\text { P:(19/6) }\end{array}$ & PFS & 7 \\
\hline $\begin{array}{l}\text { Gong X. } \\
\text { et al. }\end{array}$ & 2015 & Chinese & Lung cancer & qt-PCR & NR & NR & NR & NR & $28 / 20$ & $\begin{array}{l}Y:(9 / 12), \\
N:(19 / 8)\end{array}$ & NR & OS & 7 \\
\hline $\begin{array}{l}\text { Yuan Z. } \\
\text { et al. }\end{array}$ & 2015 & Chinese & Colon cancer & qt-PCR & $60 / 60$ & $\begin{array}{c}0.83^{\#} \\
(0.81-0.85)\end{array}$ & 0.834 & 0.856 & NR & NR & NR & NR & \\
\hline $\begin{array}{l}\mathrm{Hu} X . \\
\text { et al. }\end{array}$ & 2015 & Chinese & $\begin{array}{l}\text { Colorectal } \\
\text { cancer }\end{array}$ & qt-PCR & $60 / 20$ & $\begin{array}{c}0.75 \\
(0.65-0.87)\end{array}$ & 0.753 & 0.602 & NR & NR & NR & NR & \\
\hline $\begin{array}{l}\text { Cheng } \\
\text { H. et al. }\end{array}$ & 2014 & Chinese & Breast cancer & qt-PCR & $66 / 42$ & $\begin{array}{c}0.984 \\
(0.979-0.989)\end{array}$ & 0.9268 & 0.8988 & NR & NR & NR & NR & \\
\hline $\begin{array}{l}\text { Guan X. } \\
\text { et al. }\end{array}$ & 2013 & Chinese & $\begin{array}{l}\text { Esophageal } \\
\text { cancer }\end{array}$ & qt-PCR & $63 / 63$ & $\begin{array}{c}0.78 \\
(0.663-0.833)\end{array}$ & 0.62 & 0.81 & NR & NR & NR & NR & \\
\hline $\begin{array}{l}\text { Zhao J. } \\
\text { et al. }\end{array}$ & 2014 & Chinese & Lung cancer & qt-PCR & $100 / 100$ & $\begin{array}{c}0.775 \\
(0.681-0.868)\end{array}$ & 0.778 & 0.736 & $56 / 44$ & $\begin{array}{l}Y:(32 / 10), \\
N:(24 / 34)\end{array}$ & $\begin{array}{c}\mathrm{H}:(15 / 9), \\
\mathrm{M}:(20 / 17), \\
\mathrm{P}:(21 / 18)\end{array}$ & OS & 7 \\
\hline $\begin{array}{l}\text { Anton } \\
\text { Aparicio, } \\
\text { LM. et } \\
\text { al. }\end{array}$ & 2012 & Spanish & Renal tumors & qt-PCR & $48 / 18$ & $\begin{array}{c}0.738 \\
(0.632-0.844)\end{array}$ & NR & NR & NR & NR & NR & NR & \\
\hline
\end{tabular}

* It was a mistake in original article with AUC \& 95\% CI being 0.785 (0.486-0.763). From the original figure, we corrected them to 0.785(0.76-0.81) using the tools of Engauge Digitizer 4.1 and Origin 8.

\# It was a mistake in original article with AUC \& $95 \%$ CI being 0.80 (0.81-0.85). From the original figure, we corrected them to 0.83 ( $0.81-0.85)$ using the tools of Engauge Digitizer 4.1 and Origin 8.

Abbreviation: AUC, area under receiver operating characteristic curve; LNM, Lymph node metastasis; OS, overall survival; RFS, relapse-free survival; TSS, tumor-special survival; PFS, progression-free survival, NR, no report; Y, yes; N, no; W, well; M, modest; P, poor; H, high; NOS, Newcastle-Ottawa Scale.

prognosis, each of the 5 studies was sequentially excluded; high miR-31 expression still significantly increased the risk of OS throughout (data not shown). All of them indicated that the present pooled estimated were stable.

\section{Publication bias}

Publication bias for the association between circulating miR-31 and AUC was checked by a Begg's funnel plot under the random-effects model. Although the funnel plot seemed asymmetric, Begg's test showed no significant rank correlation with Kendall score $(Z=0.62$, $\operatorname{Pr}>|z|=0.54)$. Given this result, we performed Egger's test where evidence of significance publication bias was found ( $r=-7.24,95 \% \mathrm{CI}-11.58-2.91, P>|t|=0.004)$. Consequently, we performed trim and fill analysis to adjust the final effect; the adjusted AUC was $0.79(95 \%$ CI: $0.73-0.86)$ with $P<0.0001$ for heterogeneity. Due to 
AUC

AUC

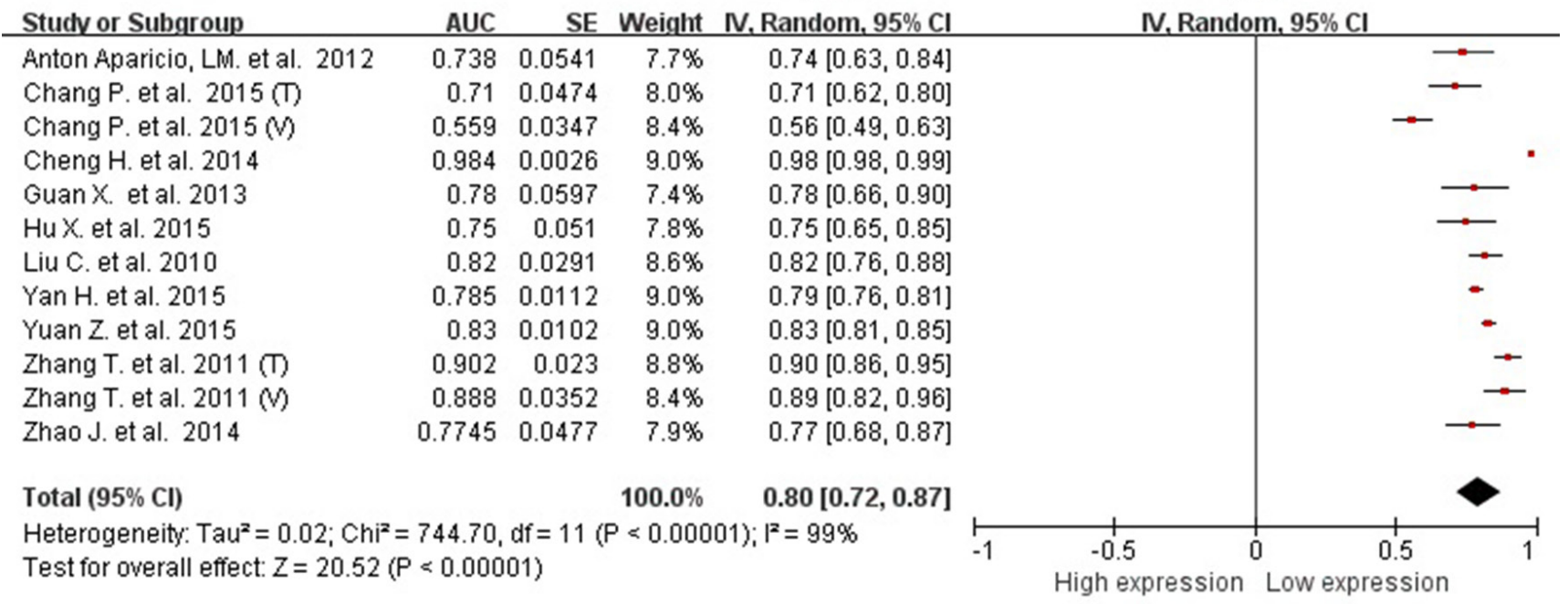

Figure 2: pooled AUC of circulating miR-31 test for the diagnosis of various cancers.

Abbreviations: AUC, area under receiver operating characteristic curve; SE, standard error; IV, inverse variance methods; CI, confidence interval.

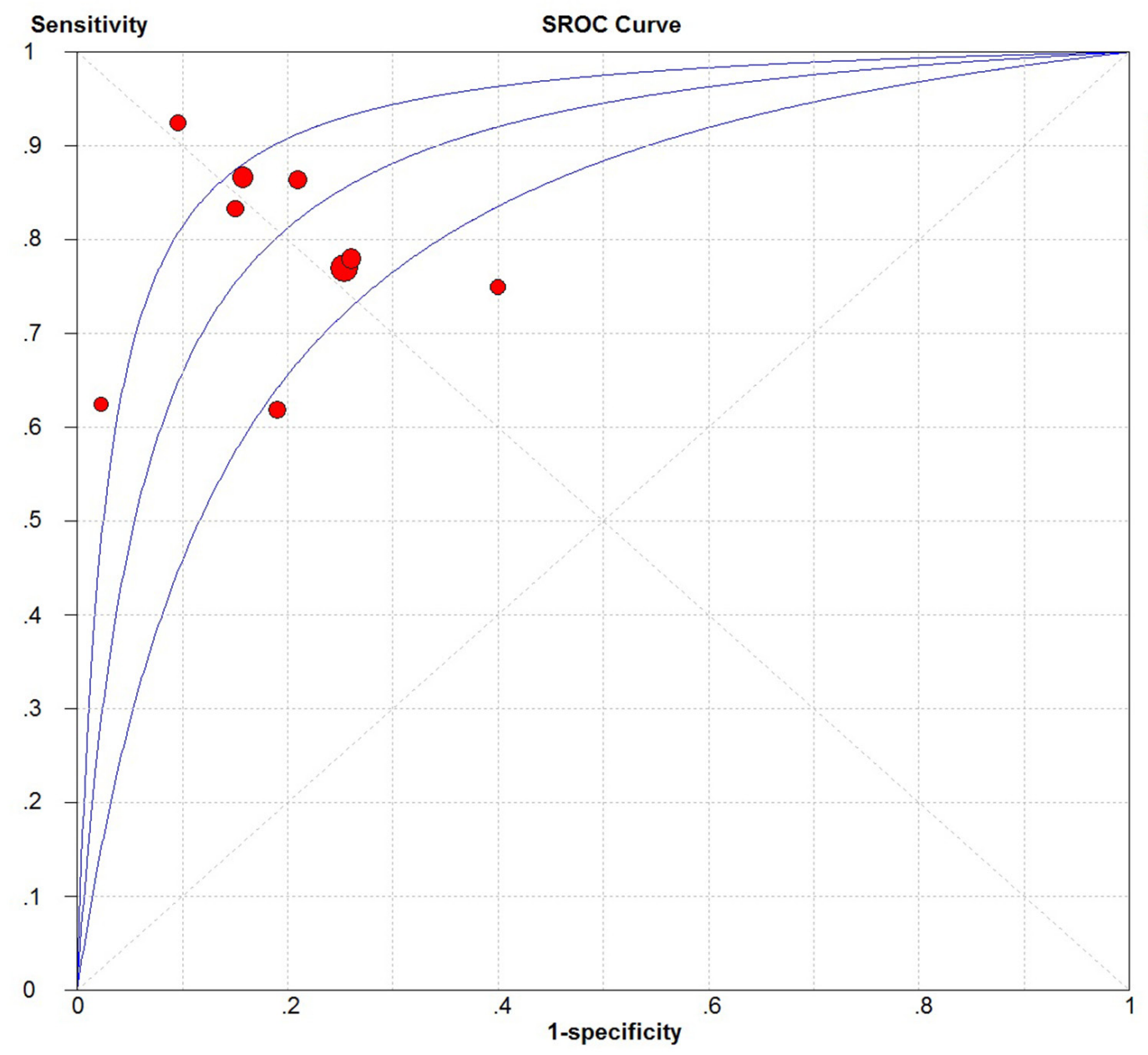

Symmetric SROC AUC $=0.8760$ $\mathrm{SE}(\mathrm{AUC})=0.0271$

$Q^{*}=0.8064$

$\mathrm{SE}\left(\mathrm{Q}^{*}\right)=0.0271$

Figure 3: The SROC curve of circulating miR-31 test for the diagnosis of various cancers. 
Table 2: The pooled effects of different types of cancer in subgroup

\begin{tabular}{lccccccc}
\hline $\begin{array}{l}\text { Types of } \\
\text { cancer }\end{array}$ & $\begin{array}{c}\text { Number of } \\
\text { tests }\end{array}$ & $\begin{array}{c}\text { AUC(95\% } \\
\mathbf{C I})\end{array}$ & $\begin{array}{c}\text { Sensitivity } \\
\mathbf{( 9 5 \%} \mathbf{C I})\end{array}$ & $\begin{array}{c}\text { Specificity } \\
\mathbf{( 9 5 \%} \mathbf{C I})\end{array}$ & $\begin{array}{c}\text { PLR } \\
\mathbf{( 9 5 \%} \mathbf{C I})\end{array}$ & $\begin{array}{c}\text { NLR } \\
\mathbf{( 9 5 \%} \mathbf{C I})\end{array}$ & $\begin{array}{c}\text { DOR } \\
\mathbf{( 9 5 \%} \mathbf{C I})\end{array}$ \\
\hline lung cancer & 2 & 0.78 & 0.77 & 0.75 & 3.03 & 0.31 & 9.92 \\
& 2 & $(0.76-0.81)$ & $(0.73-0.81)$ & $(0.70-0.79)$ & $(2.54-3.61)$ & $(0.25-0.37)$ & $(7.17-13.72)$ \\
colorectal & & 0.71 & 0.79 & 0.79 & 3.20 & 0.29 & 11.44 \\
cancer & 4 & $(0.57-0.86)$ & $(0.71-0.86)$ & $(0.68-0.87)$ & $(1.08-9.53)$ & $(0.13-0.62)$ & $(1.88-69.41)$ \\
esophageal & & 0.88 & 0.81 & 0.82 & 4.35 & 0.24 & 18.12 \\
cancer & \multirow{2}{*}{3} & $(0.82-0.96)$ & $(0.75-0.85)$ & $(0.77-0.86)$ & $(3.25-5.81)$ & $(0.10-0.54)$ & $(6.90-47.56)$ \\
\hline
\end{tabular}

${ }^{a}$ There were only two tests which reported the sensitivity and specificity.

Abbreviation: AUC, area under receiver operating characteristic curve; PLR, positive likelihood ratio; NLR, negative likelihood ratio; DOR, diagnostic odd ratio.

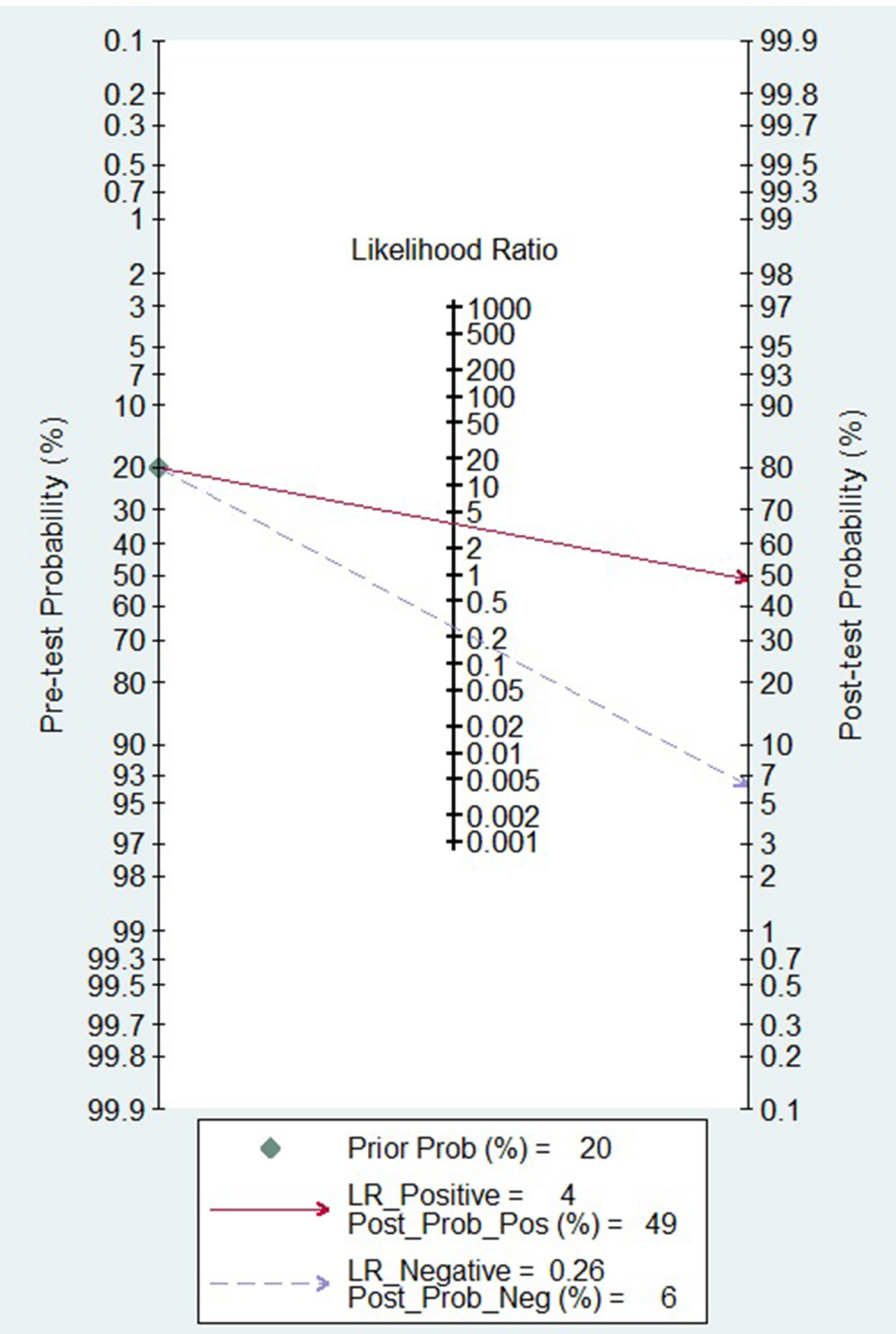

Figure 4: Fagan diagram evaluating the overall diagnostic value of miR-31 for cancer. 
circulating miR-31 acting as a diagnostic biomarker of cancer [31, 32], publication bias for test accuracy was checked by a Deek's funnel plot in the 9 tests (Figure 6) and no significant bias existed $(\mathrm{t}=1.14, P=0.292)$.

\section{DISCUSSION}

This current study aimed to assess the pooled effect of circulating miR-31 expression on detection and prognosis of cancer. The diagnostic accuracy of miR-31 for cancers was relatively high. Furthermore, high miR-31 expression significantly increased the risk of OS, although high circulating miR-31 expression was not significantly associated with poor differentiation and LNM in lung cancer. The circulating miR-31 was an effective biomarker for cancer detection and prognosis prediction.

MiR-31, a common oncomiR, has been reported to increase the risk of different types of cancer. Research in the mechanism of miR-31 found that it could target genes such as ARID1A [33], SATB2 [34], ARID1A [35],

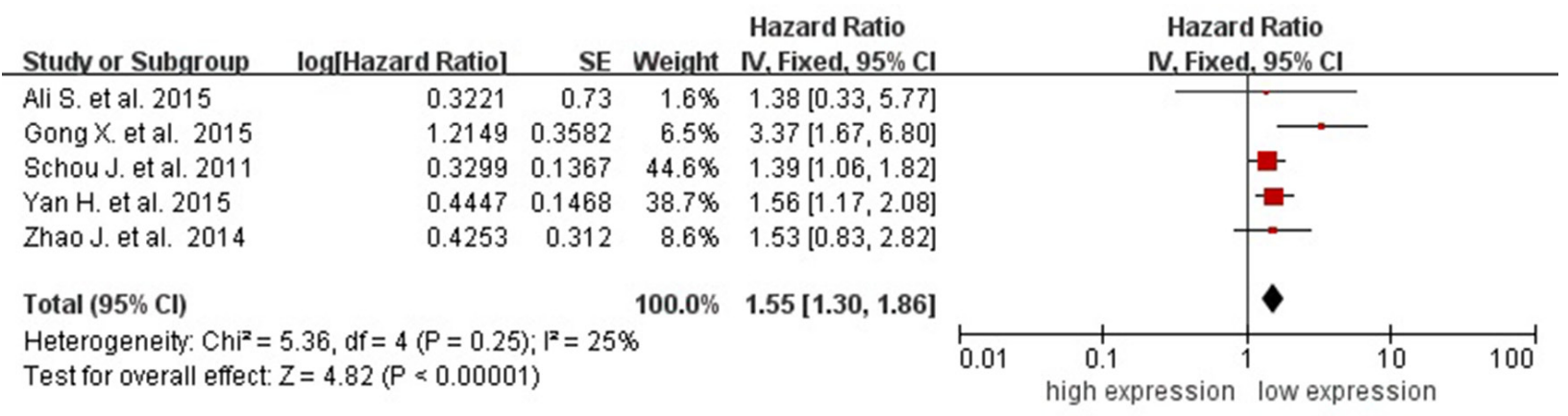

Figure 5: Forest plot of association between circulating miR-31 expression and OS.

Abbreviations: SE, standard error; IV, inverse variance methods; CI, confidence interval.

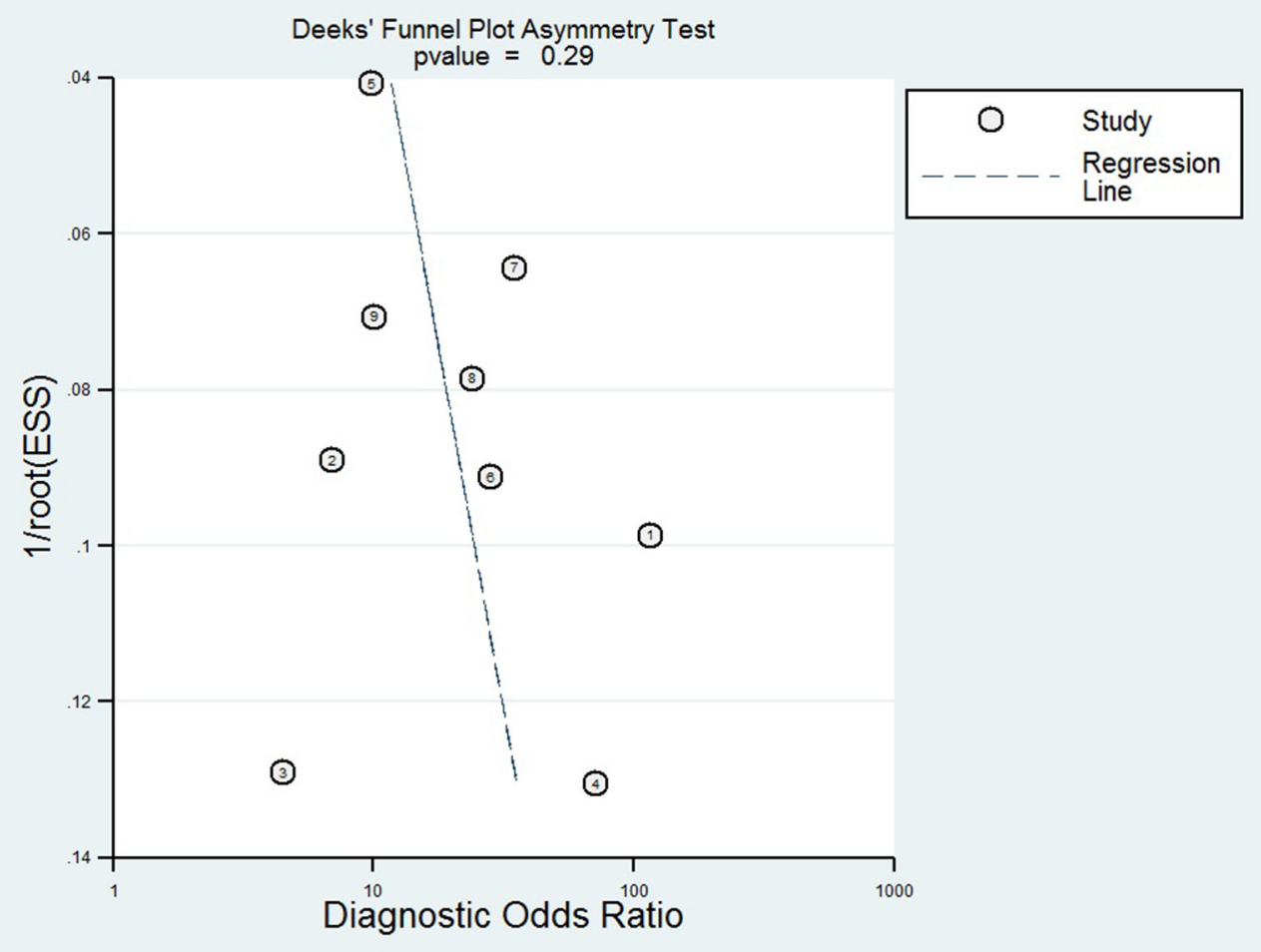

Figure 6: Deek's funnel plot to evaluate the publication bias of test accuracy. 
HuR [36], BAP1 [37], EZH2 [38], and RASA1 [39], and it could further activate oncogenes and promote tumor cell proliferation, migration and invasive capability in vitro. Furthermore, miR-31 could contribute to the epithelial-to-mesenchymal transition (EMT)[40, 41] and involved in response to chemo-radiotherapy [42-44]. However, it could also deregulate the expression of tumor activator [45, 46]. As miR-31 affects multiple targets simultaneously [7], the role of miR-31 depends on the total level and differential distribution. Circulating miR-31, always positively correlated with the level of tumor tissue $[8,47,48]$, effectively represented the total level and was predicted as a good biomarker for cancer diagnosis and prognosis surveillance [7].

In the present meta-analysis, the adjusted pooledAUC of 0.79 (95\% CI: 0.73-0.86) from 12 diagnosis tests and the DOR of 16.81 (95\% CI: 9.67-29.25) from 9 tests indicated that the performance of circulating miR-31 to detect cancer was high feasibility $[49,50]$, furthermore, there was no obvious differences among cancer types. Meanwhile, both the pooled sensitivity and specificity being 0.79 (0.76-0.82) showed circulating miR-31 had a relatively high accuracy in human cancer detection. Similar to miR-21 [51], miR-223 [52], and miR-378 [53], the pooled diagnostic value of circulating miR-31 was higher than traditional clinical markers such as CEA and CA19-9. In addition, the Fagan's nomogram showed circulating miR-31 could raise the probability of cancer detection by $29 \%$ (post-test probability $49 \%$ - pre-test probability 20\%)[54]. It all suggested that circulating miR31 was a higher effective biomarker for human cancer detection.

On the other hand, the pooled HR on OS showed circulating miR-31 was also an effective biomarker for prognosis surveillance of cancer patients. As was no significant heterogeneity among the different cancers, it epidemiologically confirmed that circulating miR-31 might have an identical effect on prognosis of cancer patients according to the same mechanism introduced above. For no significantly pooled effects of circulating miR-31 on differentiation and LNM in lung cancer, it was due to the limit of relatively small sample size (for differentiation, $\mathrm{n}=464$; for $\mathrm{LNM}, \mathrm{n}=511$ ); and it also suggested that the effect of circulating miR-31 on cancers did not only depend on influence of differentiation and LNM. Because of too few studies of circulating miR-31 on relapse-free survival (RFS), tumor-special survival (TSS), and progression-free survival (PFS), treatmentfree survival (TFS), etc. the epidemiological evidences of circulating miR-31 on chemo-radiotherapy and others were still limited and needed to be further proved.

Up to now, abundant of miRs were found to be associated with cancer and meta-analyses showed some of them played an important role in cancer detection or prognosis [51-53, 55]. For miR-31, some meta-analyses approved that it up-expressed in cancer tissues and was associated with prognosis $[8,56]$. To search for an applicable and feasible biomarker for detection and prognosis surveillance and to provide the epidemiological evidence for mechanism studies, we focused on the association of circulating miR-31 content on cancer detection and prognosis. To our best knowledge, this is the first meta-analysis to confirm the significant effect of circulating miR-31 on cancer detection and prognosis.

In the present meta-analysis, we strictly followed the PRISMA guidelines to conducted the meta-analysis, and evaluate the quality of included studies using the scales recommended by Cochrane Collaboration. There were still several limitations. First, there were only seven types of cancer included, and the studies of each type cancer as well as the samples of patients in them were few; so our results needed more large cohorts to validate. Second, because most studies were from China, the results may represent Chinese cancer patients only. Third, in spite of the fact that the present study yielded a relatively high diagnostic value, the effect of circulating miR-31 was not high enough according to the criteria of high accuracy (PLR $>10$, NLR $<0.1)$. Consequently, we recommend combining significant miRNAs from meta-analyses as a miRNAs signature to detect cancers, which could generate a more accurate result [57].

\section{MATERIAL AND METHODS}

\section{Literature search strategy}

English or Chinese studies on the role of circulating miR-31 expression in the development of human cancer were searched in EMBASE, Cochrane Library, PubMed, Wanfang databases, and China National Knowledge Infrastructure with key words (cancer or carcinoma or tumor or neoplasm or adenocarcinoma) and (microRNA-31 or miRNA-31 or miR-31) and (serum or sera or blood or plasma and "circulating"). The last search date was September 18, 2016. References of retrieved papers and conference reports were also searched to identify relevant studies.

\section{Selection criteria}

After duplicates removed, titles and abstracts of the searched articles were checked by 6 authors (YM, JL, YL, KL, YC, TW), and then the full text of eligible articles was retrieved. The eligible articles should meet the following criteria: 1) the expression of circulating miR31 was analyzed by detection/diagnosis or prognosis of cancer in human, 2) for the prognosis analysis, patients were divided into high and low expression groups by the level of circulating miR-31,3) diagnostic test indexes for detection/diagnosis (sensitivity, specificity, and AUC) or HRs for survival (overall survival [OS], relapse-free survival [RFS], tumor-special survival [TSS], progression- 
free survival [PFS]) or odd ratios (ORs) for differentiation/ LNM were provided or could be calculated from the available data; and 4) the expression of circulating miR-31 was tested by RT-PCR or fluorescence in-situ hybridization. Studies not fulfilling the criteria, reviews, and cell-line studies were excluded. Furthermore, if more than one study of the same cohort was published, only the most recent English publication was included. Consensus in searching and exclusion was resolved by discussion and with 2 other investigators (XC, JC) if needed.

\section{Data extraction and quality assessment}

The general data was extracted by 3 authors (YC, $\mathrm{HJ}, \mathrm{ZS}, \mathrm{HW}$ ) according to the following form: 1) basic information (first author's name, published year, region of cohort, cancer type, testing method of miR-31), 2) diagnostic test information (sample size, AUC, sensitivity, and specificity), 3) prognosis information (cases in each group of miR-31 (high/low), cases of differentiation/LNM in each group, and survival results [OS, RFS, TSS, PFS]). Furthermore, the reference for all effects of prognosis (ORs or HRs) was reformatted as low circulating miR31 expression, and the multivariate analysis effects were chosen for pooled analysis. The quality of diagnostic test studies was assessed by the Quality Assessment of Diagnostic Accuracy Studies 2 (QUADAS2). NewcastleOttawa Scale (NOS) was applied to assess the quality of each eligible study in prognosis analysis and the score $\geq 6$ was considered at high quality.

\section{Statistical methods}

This meta-analysis involved use of Review Manager 5.3 (Cochrane network), Meta-DiSc 1.4, and STATA 14.0. When AUC, HRs and 95\% CIs were not provided directly in some studies, Engauge Digitizer 4.1 and Origin 8 were used to analyze AUC as well as HRs and 95\% CIs from the ROC and the Kaplan-Meier curve, respectively. The heterogeneity among studies was tested by Inconsistency $\left(\mathrm{I}^{2}\right)$ and $\mathrm{Q}$ tests (chi-square test). If no statistical heterogeneity was found $\left(I^{2}<50 \%, P_{Q}\right.$ $>0.05)$, a fixed-effects model was used to estimate the pooled AUC, sensitivity, specificity, PLR, NLR, DOR, $\mathrm{OR}$ and HR. Otherwise, a random-effects model was used. Moreover, Begg's and Egger's tests were used to assess publication bias, and trim and fill analysis was used to adjust the pooled effects by STATA 14.0 [58]. All tests were two-sided and $P<0.05$ was considered statistically significant.

\section{CONCLUSIONS AND RECOMMENDATIONS}

This meta-analysis is the first to demonstrate that the circulating miR-31 has relatively high effect on cancer detection and prognosis surveillance. The expression of circulating miR-31 might be an effective biomarker for surveillance of cancer.

\section{Abbreviations}

miRs, MicroRNAs; AUC, area under receiver operating characteristic curve; PLR, NLR, positive likelihood ratio, negative likelihood ratio; DOR, diagnostic odd ratio; sROC, summary operating characteristic curve; LNM, lymph node metastasis; EMT, epithelial-tomesenchymal transition; CEA, carcinoembryonic antigen; CA, carbohydrate antigen; PRISM, Preferred Reporting Items for Systematic Reviews and Meta-Analyses; CNKI, China National Knowledge Infrastructure; TP, true positives; FP, false positives; FN, false negatives; TN, true negatives; OS, overall survival; RFS, relapse-free survival; TSS, tumor-special survival; PFS; progressionfree survival; TFS, treatment-free survival; OR, odd ratios; HR, hazard ratio; QUADAS2, Quality Assessment of Diagnostic Accuracy Studies 2; NOS, Newcastle-Ottawa Scale.

\section{Author contributions}

XC conceived of the study. YM, JL, YL, KL, YC, and TW conducted the review and screened records for eligibility. YC, HJ, ZS, and $\mathrm{HW}$ extracted data and conducted statistical analysis under the supervision of $\mathrm{XC}$ and JC. YM and YC prepared the initial report, which was read and edited by $\mathrm{XC}$ and JC. The final manuscript was read and approved by all authors.

\section{CONFLICTS OF INTEREST}

Xiaoliang Chen, Yi Liu and Yong Cao have received research grants from Shenzhen Technology Research and Development Funds (JCYJ20150403095530583， 201604130086). Yunfang Chen has supported by Shenzhen Technology Research and Development Funds (JCYJ20140416094256880 and JCYJ20160428180919224). Jinbo Lin has supported by Shenzhen Technology Research and Development Funds (JCYJ20140411150916744) and the Science \& Technology Project of Shenzhen Longgang District (201406063001026). Other authors declared no interests.

\section{FUNDING}

This study was funded by the Shenzhen Technology Research and Development Funds (JCYJ20140416094256880, JCYJ20140411150916744, JCYJ20150403095530583， JCYJ20160428180919224, 201604130086), and the Science \& Technology Project of Shenzhen Longgang District (201406063001026). 


\section{REFERENCES}

1. Kim VN, Han J, Siomi MC. Biogenesis of small RNAs in animals. Nat Rev Mol Cell Biol. 2009; 10:126-39.

2. Shen J, Hung MC. Signaling-mediated regulation of MicroRNA processing. Cancer Res. 2015; 75:783-91.

3. Ventura A, Jacks T. MicroRNAs and cancer: short RNAs go a long way. Cell. 2009; 136:586-91.

4. Pileczki V, Cojocneanu-Petric R, Maralani M, Neagoe IB, Sandulescu R. MicroRNAs as regulators of apoptosis mechanisms in cancer. Clujul Med. 2016; 89:50-55.

5. Kwan JY, Psarianos P, Bruce JP, Yip KW, Liu FF. The complexity of microRNAs in human cancer. J Radiat Res (Tokyo). 2016; 57:1106-11.

6. Pinweha P, Rattanapornsompong K, Charoensawan V, Jitrapakdee S. MicroRNAs and oncogenic transcriptional regulatory networks controlling metabolic reprogramming in cancers. Comput Struct Biotechnol J. 2016; 14:223-33.

7. Stepicheva NA, Song JL. Function and regulation of microRNA-31 in development and disease. Mol Reprod Dev. 2016; 83:654-74.

8. Guan P, Yin Z, Li X, Wu W, Zhou B. Meta-analysis of human lung cancer microRNA expression profiling studies comparing cancer tissues with normal tissues. Journal of experimental \& clinical cancer research. 2012; 31:54.

9. Luo X, Burwinkel B, Tao S, Brenner H. MicroRNA signatures: novel biomarker for colorectal cancer? Cancer Epidemiol Biomarkers Prev. 2011; 20:1272-86.

10. Severino P, Oliveira LS, Andreghetto FM, Torres N, Curioni O, Cury PM, Toporcov TN, Paschoal AR, Durham AM. Small RNAs in metastatic and nonmetastatic oral squamous cell carcinoma. BMC Med Genomics. 2015; 8:31.

11. Zheng W, Liu Z, Zhang W, Hu X. miR-31 functions as an oncogene in cervical cancer. Arch Gynecol Obstet. 2015; 292:1083-89.

12. Banno K, Yanokura M, Iida M, Adachi M, Nakamura K, Nogami Y, Umene K, Masuda K, Kisu I, Nomura H, Kataoka F, Tominaga E, Aoki D. Application of microRNA in diagnosis and treatment of ovarian cancer. Biomed Res Int. 2014; 2014:232817.

13. Izquierdo L, Ingelmo-Torres $\mathrm{M}$, Mallofré $\mathrm{C}$, Lozano JJ, Verhasselt-Crinquette M, Leroy X, Colin P, Comperat E, Roupret M, Alcaraz A, Mengual L. Prognostic value of microRNA expression pattern in upper tract urothelial carcinoma. BJU Int. 2014; 113:813-21.

14. Wang H, Zhang X, Liu Y, Ni Z, Lin Y, Duan Z, Shi Y, Wang G, Li F. Downregulated miR-31 level associates with poor prognosis of gastric cancer and its restoration suppresses tumor cell malignant phenotypes by inhibiting E2F2. Oncotarget. 2016; 7:36577-89. doi: 10.18632/ oncotarget.9288

15. Rasheed SA, Teo CR, Beillard EJ, Voorhoeve PM, Zhou W, Ghosh S, Casey PJ. MicroRNA-31 controls G protein alpha-13 (GNA13) expression and cell invasion in breast cancer cells. Mol Cancer. 2015; 14:67.

16. Ning Z, Zhu H, Li F, Liu Q, Liu G, Tan T, Zhang B, Chen S, Li G, Huang D, Meltzer SJ, Zhang H. Tumor suppression by miR-31 in esophageal carcinoma is p21-dependent. Genes Cancer. 2014; 5:436-44. doi: 10.18632/genesandcancer.38.

17. Chang PY, Chen CC, Chang YS, Tsai WS, You JF, Lin GP, Chen TW, Chen JS, Chan EC. MicroRNA-223 and microRNA-92a in stool and plasma samples act as complementary biomarkers to increase colorectal cancer detection. Oncotarget. 2016; 7:10663-75. doi: 10.18632/ oncotarget.7119.

18. Ali S, Dubaybo H, Brand RE, Sarkar FH. Differential Expression of MicroRNAs in Tissues and Plasma Co-exists as a Biomarker for Pancreatic Cancer. J Cancer Sci Ther. 2015; 7:336-46.

19. Yan HJ, Ma JY, Wang L, Gu W. Expression and significance of circulating microRNA-31 in lung cancer patients. Med Sci Monit. 2015; 21:722-26.

20. Liu CJ, Kao SY, Tu HF, Tsai MM, Chang KW, Lin SC. Increase of microRNA miR-31 level in plasma could be a potential marker of oral cancer. Oral Dis. 2010; 16:360-64.

21. Antón Aparicio LM, Medina V, Valladares Ayerbes M, Santamarina I, Aparicio Gallego G, Diaz Prado S, Quindós Varela M, Alonso-Jaudenes Curbera G. Circulating microRNAs as potential biomarkers in patients with renal tumors. J Clin Oncol. 2012; 30:405-405.

22. Zhang T, Wang Q, Zhao D, Cui Y, Cao B, Guo L, Lu $\mathrm{SH}$. The oncogenetic role of microRNA-31 as a potential biomarker in oesophageal squamous cell carcinoma. Clin Sci (Lond). 2011; 121:437-47.

23. Ren X. Serum expression and clinical significance of miR31 in non-small cell lung cancer patients [M] Master thesis, Xinjiang Medical University, (2014).

24. Gong X. Research about the Change of miR in Serum and Tissues of Lung Cancer. The Practical Joural of Cancer. 2015; 30:645-647 661.

25. Yuan ZC, Wang Y. The expression level and clinical value of serum miR-31 in colon cancer patients. Zhejiang Clinical Medical Journal. 2015; 17:2073-75.

26. Hu X, X B, Ma L. Changes of serum miR-31 expression and and its significance in patients with colorectal cancer. Shandong Yiyao. 2015; 60-61.

27. Cheng $\mathrm{X}$. Serum microRNAs as biomarkers for early combined diagnosis of breast cancer [M] Master thesis, Qingdao University, (2014).

28. Guan X. Study of serum microRNA as a diagnostic and therapeutic evaluation index for esophageal squamous cell carcinoma [M] Master thesis, Nanjing Normal University, (2013).

29. Zhao J, Chen G, Liu DH. Expression and significance of micoRNA-31 in peripheral blood of primary lung cancer patients. Journal of Zhengzhou University. 2014; 49:68486. Medical siences. 
30. Schou JV, Andersen KK, Jensen BV, Nielsen DL, Pfeiffer P, Høgdall EV, Yilmaz M, Kruhoffer M, Johansen JS. Prediction of survival in patients with metastatic colorectal cancer treated with third-line cetuximab and irinotecan through changes in microRNA expression in whole blood during treatment. J Clin Oncol. 2011; 29:3532-3532.

31. Deeks JJ, Macaskill P, Irwig L. The performance of tests of publication bias and other sample size effects in systematic reviews of diagnostic test accuracy was assessed. J Clin Epidemiol. 2005; 58:882-93.

32. Chen D, Wang YY, Chuai ZR, Huang JF, Wang YX, Liu K, Zhang LQ, Yang Z, Shi DC, Liu Q, Huang Q, Fu WL. High-resolution melting analysis for accurate detection of BRAF mutations: a systematic review and meta-analysis. Sci Rep. 2014; 4:4168.

33. Wang N, Zhou Y, Zheng L, Li H. MiR-31 is an independent prognostic factor and functions as an oncomir in cervical cancer via targeting ARID1A. Gynecol Oncol. 2014; 134:129-37.

34. Luo LJ, Yang F, Ding JJ, Yan DL, Wang DD, Yang SJ, Ding L, Li J, Chen D, Ma R, Wu JZ, Tang JH. MiR-31 inhibits migration and invasion by targeting SATB2 in triple negative breast cancer. Gene. 2016; 594:47-58.

35. Lu WC, Liu CJ, Tu HF, Chung YT, Yang CC, Kao SY, Chang KW, Lin SC. miR-31 targets ARID1A and enhances the oncogenicity and stemness of head and neck squamous cell carcinoma. Oncotarget. 2016; 7:57254-67. doi: 10.18632/oncotarget.11138.

36. Xu H, Ma J, Zheng J, Wu J, Qu C, Sun F, Xu S. MiR-31 Functions as a Tumor Suppressor in Lung Adenocarcinoma Mainly by Targeting HuR. Clin Lab. 2016; 62:711-18.

37. Yu M, Liang H, Fu Z, Wang X, Liao Z, Zhou Y, Liu Y, Wang Y, Hong Y, Zhou X, Yan X, Yu M, Ma M, et al. BAP1 suppresses lung cancer progression and is inhibited by miR-31. Oncotarget. 2016; 7:13742-53. doi: 10.18632/ oncotarget.7328.

38. Kurihara H, Maruyama R, Ishiguro K, Kanno S, Yamamoto I, Ishigami K, Mitsuhashi K, Igarashi H, Ito M, Tanuma T, Sukawa Y, Okita K, Hasegawa T, et al. The relationship between EZH2 expression and microRNA-31 in colorectal cancer and the role in evolution of the serrated pathway. Oncotarget. 2016; 7:12704-17. doi: 10.18632/ oncotarget. 7260 .

39. Kent OA, Mendell JT, Rottapel R. Transcriptional Regulation of miR-31 by Oncogenic KRAS Mediates Metastatic Phenotypes by Repressing RASA1. Mol Cancer Res. 2016; 14:267-77.

40. Cottonham CL, Kaneko S, Xu L. miR-21 and miR31 converge on TIAM1 to regulate migration and invasion of colon carcinoma cells. J Biol Chem. 2010; 285:35293-302.

41. Kim HS, Lee KS, Bae HJ, Eun JW, Shen Q, Park SJ, Shin WC, Yang HD, Park M, Park WS, Kang YK, Nam SW. MicroRNA-31 functions as a tumor suppressor by regulating cell cycle and epithelial-mesenchymal transition regulatory proteins in liver cancer. Oncotarget. 2015; 6:8089-102. doi: 10.18632/oncotarget.3512

42. Dong Z, Zhong Z, Yang L, Wang S, Gong Z. MicroRNA-31 inhibits cisplatin-induced apoptosis in non-small cell lung cancer cells by regulating the drug transporter ABCB9. Cancer Lett. 2014; 343:249-57.

43. Samuel P, Pink RC, Caley DP, Currie JM, Brooks SA, Carter DR. Over-expression of miR-31 or loss of KCNMA1 leads to increased cisplatin resistance in ovarian cancer cells. Tumour Biol. 2016;37:2565-73.

44. Lynam-Lennon N, Reynolds JV, Marignol L, Sheils OM, Pidgeon GP, Maher SG. MicroRNA-31 modulates tumour sensitivity to radiation in oesophageal adenocarcinoma. J Mol Med (Berl). 2012; 90:1449-58.

45. Ruoming W, Zhen Y, Tengteng Z, Jisheng H. Tumor suppressor microRNA-31 inhibits gastric carcinogenesis by targeting Smad4 and SGPP2. Cancer Gene Ther. 2015; 22:564-72.

46. Xu T, Qin L, Zhu Z, Wang X, Liu Y, Fan Y, Zhong S, Wang X, Zhang X, Xia L, Zhang X, Xu C, Shen Z. MicroRNA-31 functions as a tumor suppressor and increases sensitivity to mitomycin- $\mathrm{C}$ in urothelial bladder cancer by targeting integrin $\alpha 5$. Oncotarget. 2016; 7:27445-57. doi: 10.18632/ oncotarget.8479.

47. Cinpolat $\mathrm{O}$, Unal $\mathrm{ZN}$, Ismi O, Gorur A, Unal $\mathrm{M}$. Comparison of microRNA profiles between benign and malignant salivary gland tumors in tissue, blood and saliva samples: a prospective, case-control study. Braz J Otorhinolaryngol. 2016. doi: 10.1016/j.bjorl.2016.03.013.

48. Kresowik JD, Devor EJ, Van Voorhis BJ, Leslie KK. MicroRNA-31 is significantly elevated in both human endometrium and serum during the window of implantation: a potential biomarker for optimum receptivity. Biol Reprod. 2014; 91:17.

49. Walter SD. The partial area under the summary ROC curve. Stat Med. 2005; 24:2025-40.

50. Glas AS, Lijmer JG, Prins MH, Bonsel GJ, Bossuyt PM. The diagnostic odds ratio: a single indicator of test performance. J Clin Epidemiol. 2003; 56:1129-35.

51. Gao Y, Dai M, Liu H, He W, Lin S, Yuan T, Chen H, Dai S. Diagnostic value of circulating miR-21: an update metaanalysis in various cancers and validation in endometrial cancer. Oncotarget. 2016; 7:68894-908. doi: 10.18632/ oncotarget. 12028.

52. Zhou X, Ji G, Chen H, Jin W, Yin C, Zhang G. Clinical role of circulating miR-223 as a novel biomarker in early diagnosis of cancer patients. Int J Clin Exp Med. 2015; 8:16890-98.

53. Li ZZ, Shen LF, Li YY, Chen P, Chen LZ. Clinical utility of microRNA-378 as early diagnostic biomarker of human cancers: a meta-analysis of diagnostic test. Oncotarget. 2016; 7:58569-78. doi: 10.18632/oncotarget.10707. 
54. Fagan TJ. Letter: nomogram for Bayes theorem. N Engl J Med. 1975; 293:257.

55. Liu X, Luo Z, Peng H, Jiang H, Xu L. Prognostic role of miR-9 expression in various human malignant neoplasms: a meta-analysis. Onco Targets Ther. 2016; 9:3039-47.

56. Wang S, Hu J, Zhang D, Li J, Fei Q, Sun Y. Prognostic role of microRNA-31 in various cancers: a meta-analysis. Tumour biology. 2014; 35:11639-11645.
57. Teng Y, Su X, Zhang X, Zhang Y, Li C, Niu W, Liu C, Qu K. miRNA-200a/c as potential biomarker in epithelial ovarian cancer (EOC): evidence based on miRNA meta-signature and clinical investigations. Oncotarget. 2016; 7:81621-33. doi: 10.18632/oncotarget.13154.

58. Soeken KL, Sripusanapan A. Assessing publication bias in meta-analysis. Nurs Res. 2003; 52:57-60. 